\title{
Protective effects of choline against hypoxia-induced injuries of vessels and endothelial cells
}

\author{
LIAN-CHENG ZHANG $^{1 *}$, XIN JIN $^{1 *}$, ZHAO HUANG $^{2}$, ZHEN-NAN YAN $^{2}$, PEI-BING LI ${ }^{1}$, \\ RUI-FENG DUAN ${ }^{1}$, HONG FENG ${ }^{2}$, JIAN-HUA JIANG ${ }^{1}$, HUI PENG $^{1}$ and WEI LIU ${ }^{1}$ \\ ${ }^{1}$ Department of Environment and Pharmacy, Tianjin Institute of Health and Environmental Medicine, Tianjin 300050;
${ }^{2}$ Tianjin Key Laboratory of Exercise Physiology and Sports Medicine, Tianjin University of Sport, Tianjin 300381, P.R. China
}

Received August 14, 2015; Accepted January 6, 2017

DOI: $10.3892 /$ etm.2017.4276

\begin{abstract}
The current study aimed to lay a theoretical foundation for further development of choline as an anti-hypoxia damage drug. Wild-type, 3- to 5-month-old male Sprague-Dawley rats, weighing 180-220 g, were used in this study. The rats were randomly divided into a normoxic control group $(n=16)$ and a chronic intermittent hypoxia (CIH) group $(n=16)$. The effects of $\mathrm{CIH}$ on acetylcholine (ACh)-mediated endothelium-dependent vasodilatation in the rat cerebral basilar arterioles and mesenteric arterioles, as well as the protective effects of choline on the arterioles damaged by hypoxia were observed. Moreover, the effects of choline on endothelial cell proliferation during hypoxia were observed, and choline's functional mechanism further explored. The ACh-mediated vasodilatation of rat cerebral basilar and mesenteric arterioles significantly reduced during hypoxia $(\mathrm{P}<0.01)$. Choline significantly increased dilation in the rat cerebral basilar $(\mathrm{P}<0.01)$ and mesenteric arterioles $(\mathrm{P}<0.05)$ damaged by $\mathrm{CIH}$ compared with those in the control group. In addition, under hypoxic conditions, choline significantly promoted the proliferation of rat aortic endothelial cells $(\mathrm{P}<0.05)$ and significantly reduced lactate dehydrogenase activity in the cell culture supernatant in vitro $(\mathrm{P}<0.05)$. Furthermore, the effect of choline could be related to its ability to significantly increase the secretion of
\end{abstract}

Correspondence to: Dr Wei Liu, Department of Environment and Pharmacy, Tianjin Institute of Health and Environmental Medicine, 1 Dali Road, Tianjin 300050, P.R. China

E-mail: liuwei9668@163.com

*Contributed equally

Abbreviations: ACh, acetylcholine; $\alpha 7 \mathrm{nAChR}, \alpha 7$ non-neuronal nicotinic acetylcholine receptor; $\mathrm{CIH}$, chronic intermittent hypoxia; ET-1, endothelin-1; LDH, lactate dehydrogenase; MLA, mecamylamine; RAECs, rat aortic endothelial cells; SD rats, Sprague-Dawley rats; VECs, vascular endothelial cells; VEGF, vascular endothelial growth factor

Key words: chronic intermittent hypoxia, vasodilator effects, choline, vascular endothelium, cell proliferation vascular endothelial growth factor $(\mathrm{P}<0.01)$ and activation of $\alpha 7$ non-neuronal nicotinic acetylcholine receptors under hypoxia $(\mathrm{P}<0.01)$. This study demonstrated that choline could have protective effects against hypoxic injuries.

\section{Introduction}

Hypoxia is an environmental stress factor that induces damage to cells, tissues and organs, and is associated with numerous types of disease. Vascular endothelial cells (VECs), as target cells of hypoxic damage, are susceptible to hypoxia and serve a key function in regulating the activity of blood vessels, as well as in the occurrence and development of numerous hypoxia-related diseases and injuries (1). Under normal circumstances, VECs serve as a barrier between the tissues and blood lining in the endothelial layer of blood vessels (2). If the endothelial layer is damaged, VECs lose their original structure and function, directly causing defects in the endothelial layer, failure of intimal integrity and vascular dysfunction. This is the first step in the development of peripheral vascular injuries caused by hypoxia (3-5). However, it is important to recognize the endothelium as a critical secretory organ with both receptor and effector functions. It can sense a range of external physical and chemical stimuli, and synthesize and secrete important vasoactive substances, such as nitric oxide, endothelin-1 (ET-1) and vascular endothelial growth factor (VEGF) (6-9). These substances function in maintaining the vasomotor state, vascular permeability and a dynamic balance of the internal environment in a variety of diseases and injuries of many pathophysiological processes.

When exposed to hypoxic conditions, VEC function may be disrupted, causing an imbalance of the synthesis and secretion of various regulatory factors and vasoactive substances. This may eventually result in an increase in vascular permeability, a decrease in antioxidant capacity and a variety of hypoxia-related diseases and injuries (3-5). Therefore, the primary task in preventing and treating hypoxia-related disease is to protect VECs from damage and maintain their normal physiological function.

Choline is an essential water-soluble nutrient belonging to the B-complex family of vitamins $(10,11)$. Adolph Strecker first identified it in ox bile in 1862 (12) and in 1932, it was recognized by Best, Hershey and Huntsman as an essential dietary 
nutrient (13). Since then, it has been found that choline plays a key role in many physiological processes such as signaling transduction, biosynthesis and integrity of cell membranes, DNA and histone methylation, and neurotransmitter acetylcholine (ACh) synthesis (14-16). It has also been found that choline metabolism changes under hypoxic exposure $(17,18)$.

In the current study, the influences of chronic intermittent hypoxia $[\mathrm{CIH}$; this refers to long-term, repetitive exposure to hypoxia, interspersed with periods in normoxic conditions $(19,20)$ ] on ACh-mediated endothelium-dependent vasodilatation function of the rat cerebral basilar arterioles and mesenteric arterioles were observed, as well as the protective effects of choline on the arterioles damaged by hypoxia. Furthermore, the effect of choline on cell proliferation, lactate dehydrogenase (LDH) release, and VEGF expression under hypoxic conditions in vitro was observed, as well as the influence of mecamylamine [(MLA; an antagonist of the $\alpha 7$ non-neuronal nicotinic acetylcholine receptor $(\alpha 7 \mathrm{nAChR})]$ on choline effects. As one of the B-complex family of vitamins, choline serves a key role in a number of physiological processes such as signaling transduction, DNA and histone methylation, and neurotransmitter ACh synthesis. The aim of this study was to lay a theoretical foundation for further developing choline as an anti-hypoxia damage drug.

\section{Materials and methods}

Experimental animals and drugs. A total of 30 wild-type, 3- to 5-month-old male Sprague-Dawley (SD) rats, weighing 180-220 g, provided by the Experimental Animal Center of Beijing Academy of Military Medical Sciences (Beijing, China), were used in this study. The rats were housed individually at a temperature of $18-24^{\circ} \mathrm{C}$ and given ad libitum access to food and water. The care and use of animals in the experiments met the standards set out in the Guide for the Care and Use of Laboratory Animals from the National Institutes of Health (Bethesda, MD, USA) and closely complied with the Animal Care and Use Committee of the Tianjin Institute of Health and Environmental Medicine (Tianjin, China). The protocol was approved by the Committee on the Ethics of Animal Experiments of the Tianjin Institute of Health and Environmental Medicine (permit no. 2013-D-3604). All efforts were made to lower the number of animals used and to reduce animal stress. Choline chloride $(\mathrm{ChCl}), \mathrm{ACh}$ and ET-1 were purchased from Sigma-Aldrich (Merck KGaA, Darmstadt, Germany).

Animal grouping and treatment with $\mathrm{CIH}$. The rats were randomly divided into a normoxic control group (no treatment, $n=16$ ) and a CIH group (treatment with $\mathrm{CIH}, \mathrm{n}=16$ ). Half the rats in each group were used to study arterial endothelial activity and the other half to study the selective dilatation effects of choline.

Animals from the CIH group were separately housed in cages, which were placed into a Plexiglas chamber $(40 \times 30 \times 30 \mathrm{~cm})$. At the beginning of hypoxia, nitrogen was pumped into the chamber to reduce the oxygen concentration. This was continuously measured using an oxygen concentration monitor (CYES-II, Shanghai Scientific Instruments, Shanghai, China) and was stabilized at a level of $10 \pm 0.5 \%$ (which mimics the hypoxic environment of $6,000 \mathrm{~m}$ above sea level) for $8 \mathrm{~h}$ (8:00 a.m. to 4:00 p.m.) via an exhaust valve controlled by an automatic computer system. The chamber contained a small hole that allowed the pressure inside to remain consistent with the external environment. Carbon dioxide and water vapor in the chamber were absorbed with soda lime and anhydrous calcium chloride, respectively. Intermittent hypoxia $(8 \mathrm{~h} / \mathrm{day}$, 6 days/week) lasted for 12 weeks. The treatment of animals from the normoxic control group was the same as that of the $\mathrm{CIH}$ group except that they were not given $\mathrm{CIH}$ treatment. At the end of the $\mathrm{CIH}$ exposure duration, animals were administered $1-2 \%$ isoflurane through a face mask for anesthesia prior to sacrifice by decapitation and surgical procedures were performed.

Arterial tension measurement. After the rats were sacrificed by decollation, intestinal and brain tissues were rapidly removed and placed into culture dishes containing Krebs-Ringer nutrient solution (118.3 mM NaCl, $4.7 \mathrm{mM} \mathrm{KCl}$, $2.5 \mathrm{mM} \mathrm{CaCl}_{2}, 1.2 \mathrm{mM} \mathrm{KH} \mathrm{PO}_{4}, 25 \mathrm{mM} \mathrm{NaHCO}, 1.2 \mathrm{mM}$ $\mathrm{MgSO}_{4}, 0.026 \mathrm{mM}$ EDTA and $11.1 \mathrm{mM}$ glucose) at $4^{\circ} \mathrm{C}$. Under a light microscope, the rat basilar arteries (300- $\mu$ m diameter) and the third-order branches of mesenteric arteries $(250-\mu \mathrm{m}$ diameter) were carefully dissected using microtweezers and cut into $\sim 2$ - $\mathrm{mm}$ microarterial rings. The arterial rings were then mounted in a wire myograph (Model 610M; Danish Myo Technology AS, Aarhus, Denmark) as described in a previous study (21) and fixed into the $37^{\circ} \mathrm{C}$ thermostatic bath of a microvascular tension meter (Danish Myo Technology AS). When the tension index became stable, 6 nM ET-1 was added into basilar arteries and $40 \mu \mathrm{M}$ potassium chloride into mesenteric arteries to induce a precontracted model. The arterial endothelial activity was evaluated by ACh with single or cumulative concentration, which is a classical tool used in medicine to assess whether the vascular endothelium is intact or impaired. In another experiment, $\mathrm{ChCl}$ was cumulatively mixed into the $37^{\circ} \mathrm{C}$ thermostatic bath in accordance with concentration-response relationships to observe the effects of the drug on the dilation of cerebral basilar or mesenteric arteries.

Analysis of the effects of acute hypoxic exposure. A total of 48 rats were used in the analysis of acute hypoxic exposure. As described above, the rats were housed individually under a 12-h light/dark cycle at a temperature of $18-24^{\circ} \mathrm{C}$ and relative humidity of $56 \pm 10 \%$ and provided ad libitum access to food and water under normoxic conditions. After the rats were anesthetized with $1-2 \%$ isoflurane, they were sacrificed by decapitation, the mesenteric arteries were dissected and cut into $\sim$-mm microarterial rings. The arterial rings were randomly divided into three groups: Normoxic control (no treatment, $\mathrm{n}=16$ ), $\mathrm{H} 1$ (pretreatment with hypoxia for $1 \mathrm{~h}, \mathrm{n}=16$ ) and $\mathrm{H} 3$ (pretreatment with hypoxia for $3 \mathrm{~h}, \mathrm{n}=16$ ). All the arterial rings were fixed into the $37^{\circ} \mathrm{C}$ thermostatic bath of the microvascular tension meter and arterial tension measurements were conducted. This was carried out as described above, except that the arterial rings of the $\mathrm{H} 1$ and $\mathrm{H} 3$ groups were placed into a hypoxic incubator containing $1 \% \mathrm{O}_{2}, 92 \% \mathrm{~N}_{2}$ and $5 \% \mathrm{CO}_{2}$, for 1 and $3 \mathrm{~h}$, respectively, before they were fixed into the $37^{\circ} \mathrm{C}$ thermostatic bath of the microvascular tension meter. 
Cell culture and treatment. A total of 5 wild-type, 3- to 5-month-old male Wistar rats, weighing 180-220 g, provided by the Experimental Animal Center of Beijing Academy of Military Medical Sciences (Beijing, China), were used for the RAECs acquisition. The rats were housed individually under a $12-\mathrm{h}$ light/dark cycle at a temperature of $18-24^{\circ} \mathrm{C}$ and relative humidity of $56 \pm 10 \%$ and provided ad libitum access to food and water. The care and use of animals in the experiments met the standards set out in the Guide for the Care and Use of Laboratory Animals from the National Institutes of Health (Bethesda, MD, USA) and closely complied with the Animal Care and Use Committee of the Tianjin Institute of Health and Environmental Medicine (Tianjin, China). The protocol was approved by the Committee on the Ethics of Animal Experiments of the Tianjin Institute of Health and Environmental Medicine (permit no. 2013-D-3806). Animals were administered 1-2\% isoflurane through a face mask for anesthesia prior to sacrifice by cervical dislocation. The chest was opened under sterile conditions and the aortas were quickly removed and washed twice using D-Hanks solution (Beijing Leagene Biotechnology Co., Ltd., Beijing, China; $\mathrm{pH}=7.2$ ) to wash away the blood. The connective tissues surrounding blood vessels were excluded, and the blood vessels were longitudinally cut open, and sliced into $1 \mathrm{~mm}^{2}$ sections, which were affixed to the bottom of a Petri dish. M199 medium (Gibco; Thermo Fisher Scientific, Inc., Waltham, MA, USA) supplemented with $20 \%$ fetal bovine serum (Hyclone; GE Healthcare, Logan, UT, USA), $100 \mathrm{U} / \mathrm{ml}$ penicillin, and $100 \mathrm{mg} / \mathrm{ml}$ streptomycin (Thermo Fisher Scientific, Inc.) was slowly added to the Petri dish, once the chips were firmly affixed to the bottom. The Petri dish was transferred to an incubator at $37^{\circ} \mathrm{C}$ and $5 \%$ $\mathrm{CO}_{2}$ for $72 \mathrm{~h}$. When a small amount of RAECs were visible, half the medium was replaced. The medium was completed replaced after 5 days, when a large number of cells had proliferated. Finally, Rat aortic endothelial cells (RAECs) were identified using an antibody against CD31 labeled with FITC (ab33858, 1:200; Abcam, Cambridge, UK). The cells from 4 to 10 generations were selected to be used in the experiments, and when cells at the logarithmic growth phase were digested into a single cell suspension and plated into 96-well plates with $10^{2}-10^{4}$ cells/well, in an M199 medium supplemented with $20 \%$ fetal bovine serum, $100 \mathrm{U} / \mathrm{ml}$ penicillin and $100 \mathrm{mg} / \mathrm{ml}$ streptomycin in a $37^{\circ} \mathrm{C}, 5 \% \mathrm{CO}_{2}$ incubator until they reached $\sim 90 \%$ confluence. The cells were then randomly divided into two groups and all of them were cultured in the serum-free M199 medium. One group remained in the normoxic incubator containing $5 \% \mathrm{CO}_{2}$ at $37^{\circ} \mathrm{C}$, and the other was placed into a $37^{\circ} \mathrm{C}$ incubator containing $1 \% \mathrm{O}_{2}, 92 \% \mathrm{~N}_{2}$ and $5 \% \mathrm{CO}_{2}$.

Analysis of the proliferation of RAECs. The proliferation and the survival rates of RAECs cultured in normoxic or hypoxic conditions were measured by MTS assay (ab197010; Abcam) in accordance with the manufacturer's instructions. In brief, cells at the logarithmic growth phase were digested into a single cell suspension and plated into 96-well plates with $10^{2}-10^{4}$ cells/well, $100 \mu 1$ per well. Cells were cultured in $37^{\circ} \mathrm{C}$ normoxic or hypoxic incubator for $48 \mathrm{~h}$. $20 \mu \mathrm{l}$ MTS solution was added per well, and incubated at $37^{\circ} \mathrm{C}$ for $2 \mathrm{~h}$. Finally, the 96-well plates were measured under $490 \mathrm{~nm}$ wavelength, and the cell growth curve was drawn.
LDH assay to determine the degree of cell damage. $\mathrm{LDH}$ is an important glycolytic enzyme widely present in the cytoplasm, so determining its activity levels in the cell culture supernatant indicates the degree of cell damage (22). The activity of extracellular LDH was measured using an LDH Detection kit (Sigma-Aldrich; Merck KGaA). In brief, RAECs at the logarithmic growth phase were digested and plated into 96-well plates with $10^{2}-10^{4}$ cells/well, in an M199 medium supplemented with $20 \%$ fetal bovine serum in the $37^{\circ} \mathrm{C}$ normoxic or hypoxic incubator. Cells were cultured until they adhered to the bottom, then the medium was replaced with a serum-free medium. Once the cells were treated under the normoxic or hypoxic conditions as described previously, they were collected with $1 \%$ bovine serum albumin analysis solution. Following this, $200 \mu \mathrm{l}$ analysis solution containing $10^{4}$ cells was added to 96 -well plates and incubated for $2 \mathrm{~h}$ at $37^{\circ} \mathrm{C}$ in a normoxic or hypoxic incubator. Cells were then centrifuged for $10 \mathrm{~min}$ at $250 \mathrm{x} \mathrm{g}$, and $100 \mu \mathrm{l}$ supernatant per well was immediately transferred to new 96-well plates. To each well, $100 \mu \mathrm{l}$ reaction mixture was added and incubated $30 \mathrm{~min}$ at room temperature. Finally, the absorbance of all samples was measured under $490 \mathrm{~nm}$ wavelength.

Determination of VEGF levels in cultured supernatant. After RAECs were treated with normoxic or hypoxic conditions as described above, the serum-free culture supernatant was collected (as described in LDH assay to determine the degree of cell damage), and the levels of VEGF in the supernatant were measured using commercially available ELISA kits (Cell Signaling Technology, Inc., Danvers, MA, USA), which contain the Wash Solution, Detection Antibody, Streptavidin solution and Stop Solution, according to a standard enzyme immunoassay procedure. In brief, when the serum-free cell culture supernatant was collected, $100 \mu \mathrm{l}$ of each standard and sample was immediately added into appropriate wells. The plates was covered and incubated for $2.5 \mathrm{~h}$ at room temperature with gentle agitation. The solution was discarded and washed 4 times with 1X Wash Solution. Following this, $100 \mu 1$ of 1X prepared Detection Antibody was added to each well and the plates were incubated for $1 \mathrm{~h}$ at room temperature with gentle agitation. The wash procedure was repeated and $100 \mu 1$ of prepared Streptavidin solution was added to each well followed by $45 \mathrm{~min}$ incubation at room temperature and the wash procedure. TMB One-Step Substrate Reagent (100 $\mu \mathrm{l})$ was added to each well. Finally, following $30 \mathrm{~min}$ incubation at room temperature in the dark with gentle agitation, $50 \mu \mathrm{l}$ Stop Solution was added, and the absorbance of all samples was measured under $450 \mathrm{~nm}$ wavelength immediately.

Statistical analysis. All data are presented as the mean \pm standard error. Results were analyzed using the Student's t-test and analysis of variance with SPSS version14.0 software (SPSS, Inc., Chicago, IL, USA), and $\mathrm{P}<0.05$ was considered to indicate a statistically significant difference.

\section{Results}

Effect of CIH on the endothelial activity of rat cerebral basilar and mesenteric arterioles. The endothelial activity of cerebral basilar and mesenteric arterioles of rats exposed to normoxic 
or $\mathrm{CIH}$ conditions were studied using $10 \mu \mathrm{M}$ ACh. The results showed that the dilation of the normoxic control group was $21.41 \pm 7.18 \%$ when it was treated with $10 \mu \mathrm{M} \mathrm{ACh}$, and that of the CIH group was $12.27 \pm 4.09 \%$ (Fig. 1A). The relaxation rate of the cerebral basilar arterioles was significantly lower in the $\mathrm{CIH}$ group compared with the normoxic control group $(\mathrm{P}<0.01)$, which suggested that the rat brain VECs had been injured by $\mathrm{CIH}$ treatment, and their endothelium-dependent relaxation response to $\mathrm{ACh}$ weakened.

Likewise, vascular endothelial damage caused by $\mathrm{CIH}$ was also found in the mesenteric arterioles (Fig. 1B). The dilation of the normoxic control group was $46.03 \pm 15.34 \%$ after treatment with $10 \mu \mathrm{M} \mathrm{ACh}$, and that of the $\mathrm{CIH}$ group was $31.13 \pm 10.37 \%$. The relaxation rate of the mesenteric arterioles was significantly lower in the $\mathrm{CIH}$ group compared with the normoxic control group $(\mathrm{P}<0.01)$. This suggested that $\mathrm{CIH}$ exposure caused rat systemic peripheral resistance vessel endothelium injuries and weakened the endothelium-dependent relaxation response to $\mathrm{ACh}$.

Vasodilator effects of choline on rat cerebral basilar arterioles and mesenteric arterioles treated with $\mathrm{CIH}$. The maximum relaxation rates of cerebral basilar arterioles in the normoxic control and $\mathrm{CIH}$ groups after treatment with choline were $8.06 \pm 2.68$ and $19.55 \pm 6.51 \%$, respectively $(\mathrm{P}<0.01$; Fig. $2 \mathrm{~A})$. The relaxation rate was significantly higher in the hypoxia group compared with the control group $(\mathrm{P}<0.05$ for choline concentrations $10^{-10}, 10^{-9}$ and $10^{-8} \mathrm{~mol} / 1, \mathrm{P}<0.01$ for choline concentrations $10^{-7}, 10^{-6}, 10^{-5}$ and $\left.10^{-4} \mathrm{~mol} / \mathrm{l}\right)$. This indicated that the vasodilator effect of choline on the cerebral basilar arterioles was stronger in the $\mathrm{CIH}$ group than in the control group, suggesting that choline could have protective effects against cerebral ischemia induced by hypoxia and improve cerebral circulation.

The vasodilator effects of choline on the mesenteric arterioles showed the same trend. The maximum relaxation rates of the normoxic control and the $\mathrm{CIH}$ groups after treatment with choline were $13.32 \pm 4.44$ and $29.18 \pm 9.72 \%$, respectively $(\mathrm{P}<0.05$; Fig. 2B). The relaxation rate was significantly higher in the hypoxia group compared with the control group at choline concentrations of $10^{-6}, 10^{-5}$ and $10^{-4} \mathrm{~mol} / 1(\mathrm{P}<0.05)$. This indicated that the vasodilator effect of choline on the mesenteric arterioles was greater in the $\mathrm{CIH}$ group than in the normoxic control group, suggesting that choline could have vasodilator effects against peripheral resistance vascular injuries induced by hypoxia.

The vasodilator effect of choline on normal arterioles was weaker than that on arterioles injured by hypoxia. The selectivity may contribute to the function of choline, currently used for treating stroke, hypertension and other acute and chronic diseases caused by hypoxia, with the advantage of less adverse reactions to the normal human. Therefore, it suggests that choline may be a potential treatment for these diseases.

Effects of acute hypoxic exposure and choline on the endothelial activity of rat isolated mesenteric arterioles. In the aforementioned experiments, it was found that the endothelial activity of rat cerebral basilar and mesenteric arterioles was affected by $\mathrm{CIH}$, and choline showed protective effects against vascular endothelium damage caused by CIH. The
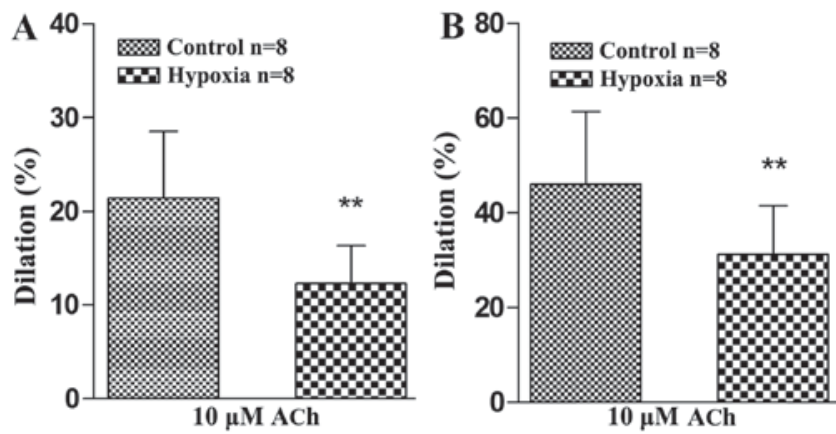

Figure 1. Effects of chronic intermittent hypoxia on endothelium-dependent vasodilatation induced by $\mathrm{ACh}$ in rat cerebral basilar and mesenteric arterioles. (A) Vasodilator response of cerebral basilar arteries to $10 \mu \mathrm{M} \mathrm{ACh}$, after being precontracted with $6 \mathrm{nM}$ endothelin 1. (B) Vasodilator response of mesenteric arteries to $10 \mu \mathrm{M}$ ACh, after being precontracted with $40 \mu \mathrm{M}$ potassium chloride. ${ }^{* *} \mathrm{P}<0.01$ vs. control. ACh, acetylcholine.

current study subsequently investigated whether these effects were due to $\mathrm{CIH}$ treatment specifically, or hypoxia treatment in general.

Healthy rat isolated mesenteric arteries were exposed to acute hypoxic conditions for $1 \mathrm{~h}$ ( $\mathrm{H} 1$ group) or $3 \mathrm{~h}(\mathrm{H} 3$ group) to observe the effects of acute hypoxic exposure on their vascular endothelial activity. To investigate the effect of acute hypoxic exposure on the endothelial activity of rat isolated mesenteric arterioles, then the arterioles was treated with $10 \mu \mathrm{M} \mathrm{ACh}$. After treatment with $\mathrm{ACh}$, the vascular endothelium-dependent relaxation of the $\mathrm{H} 1$ group was found to have no significant change compared with the control group (Fig. 3A). The relaxation response slightly decreased in the H3 group compared with the control group, but no significant difference was noted. The ACh half maximal effective concentration $\left(\mathrm{EC}_{50}\right)$ values of the control, $\mathrm{H} 1$ and $\mathrm{H} 3$ groups were $3.049 \times 10^{-8}, 3.721 \times 10^{-8}$ and $5.490 \times 10^{-8} \mathrm{M}$, respectively.

Furthermore, the vasodilator effect of choline on the control, $\mathrm{H} 1$ and $\mathrm{H} 3$ groups was investigated. The response was found to be greater for the $\mathrm{H} 1$ group than for the control group, and the strongest effect was found in the H3 group. However, the differences between groups were not significant (Fig. 3B). The choline $\mathrm{EC}_{50}$ values of the control group, $\mathrm{H} 1$ group and $\mathrm{H} 3$ group were $7.995 \times 10^{-7}, 3.899 \times 10^{-7}$ and $1.176 \times 10^{-7} \mathrm{M}$, respectively. The results suggested that the vasodilator effects of choline on the mesenteric arterioles under acute hypoxic conditions gradually increased with time, but no significant differences were identified.

Effects of choline on promoting cell proliferation and protecting against cell damage under normoxic conditions. The effects of choline on promoting endothelial cell proliferation under hypoxic conditions and protecting endothelial cells against the damage caused by hypoxia were observed.

Normoxic conditions. RAECs were treated with choline for $24 \mathrm{~h}$ under normoxic conditions. A choline dosage of $1,000 \mu \mathrm{M}$ was found to significantly increase the proliferation of endothelial cells compared with the control ( $\mathrm{P}<0.01$; Fig. 4A), but the LDH content in the supernatant did not increase significantly at any choline concentration tested (Fig. 4B). The same results and trends were found in the cells treated with choline 

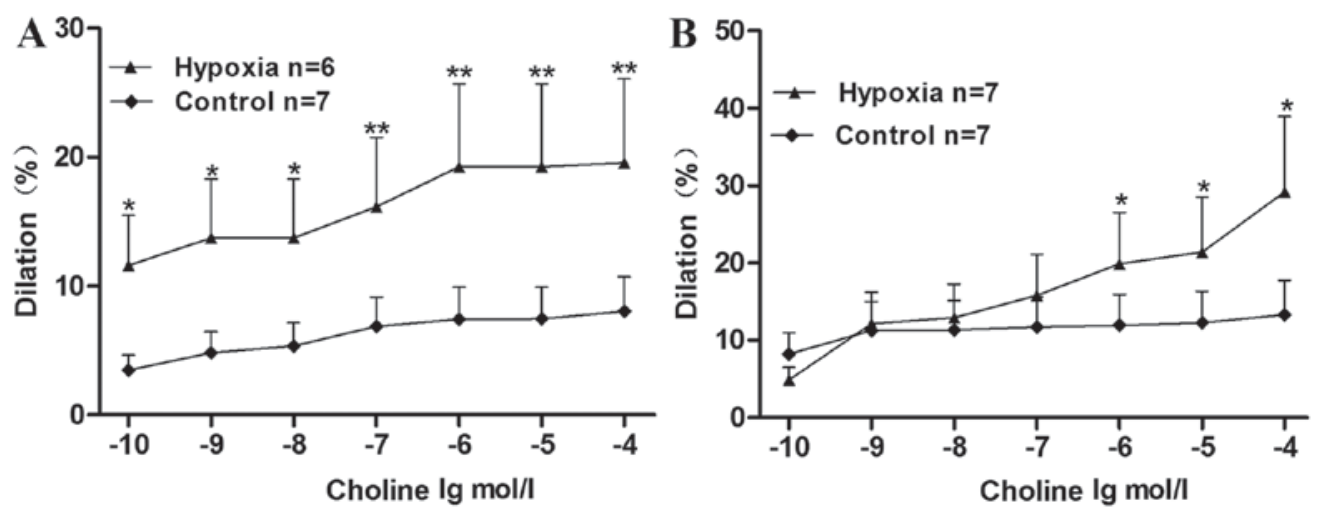

Figure 2. Vasodilator effects of choline on chronic intermittent hypoxia-treated rat cerebral basilar and mesenteric arterioles. (A) Vasodilator effects of choline (of varying concentrations between $10^{-10}$ and $10^{-6} \mathrm{~mol} / \mathrm{l}$ ) on endothelium-intact cerebral basilar aorta rings, precontracted with $6 \mathrm{nM}$ endothelin 1 . (B) Vasodilator effects of choline (of varying concentrations between $10^{-10}$ and $10^{-6} \mathrm{~mol} / \mathrm{l}$ ) on endothelium-intact mesenteric aorta rings, precontracted with $40 \mu \mathrm{M}$ potassium chloride. ${ }^{*} \mathrm{P}<0.05,{ }^{* *} \mathrm{P}<0.01$ vs. control.
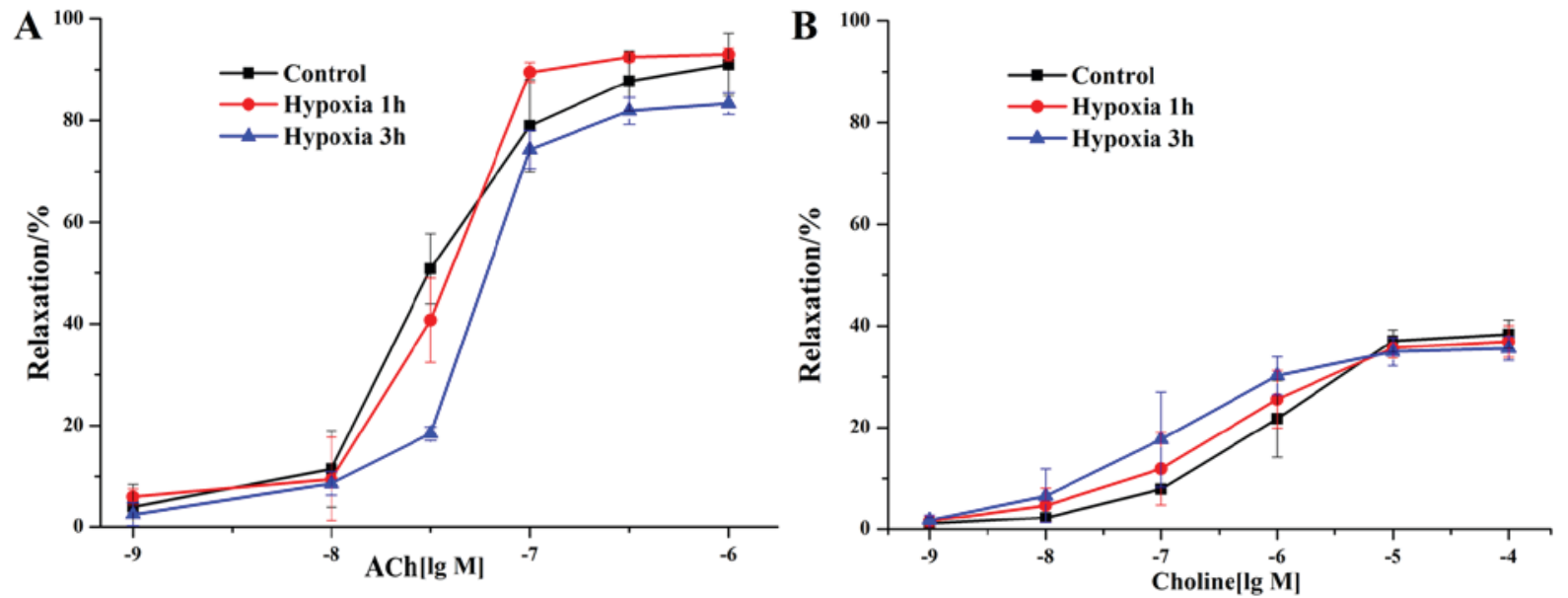

Figure 3. Effects of acute hypoxic exposure and choline on the endothelial activity of rat isolated mesenteric arterioles. (A) Effects of acute hypoxic exposure on the ACh-mediated endothelial activity of rat mesenteric arterioles. Healthy, normal rat isolated arteries were exposed to acute hypoxic conditions for 1 or $3 \mathrm{~h}$ to observe the effects of acute hypoxic exposure on their vascular endothelial activity. (B) Effects of choline on the endothelial activity of rat mesenteric arterioles under acute hypoxic exposure. ACh, acetylcholine.

under normoxic conditions for $48 \mathrm{~h}$, although a significant increase in endothelial cell proliferation was observed from concentrations of 0.1 to $1,000 \mu \mathrm{M}(\mathrm{P}<0.01$; Fig. 4C and D).

Hypoxic conditions. The effects of choline on promoting cell proliferation and protecting against damage under hypoxic conditions were determined (Fig. 5). Under hypoxic conditions, choline with a concentration from 0.1 to $10 \mu \mathrm{M}$ was able to significantly increase proliferation of RAECs, when choline treatment was for $24(\mathrm{P}<0.05$; Fig. 5A and $\mathrm{C})$. Choline treatment for both 24 and $48 \mathrm{~h}$ significantly reduced LDH activity in the cell supernatant, compared with the control $(\mathrm{P}<0.05$; Fig. 5B and D).

Mechanisms of choline in promoting endothelial cell proliferation. The mechanisms by which choline promotes endothelial cell proliferation were explored. First, the effect of choline on VEGF secretion of RAECs under hypoxic conditions was investigated. It was found that the quantity of VEGF in the endothelial cell culture supernatant significantly increased under hypoxic conditions for $24 \mathrm{~h}(\mathrm{P}<0.05$; Fig. 6A). When the RAECs were incubated with $10 \mu \mathrm{M}$ choline, the quantity of VEGF in the supernatant increased further $(\mathrm{P}<0.01$; Fig. 6A). Though there was no significant difference between the choline-treated RAECs and the hypoxic group $(\mathrm{P}>0.05$; Fig. 6A), but there was a slight increase. This indicated that hypoxia promoted VEGF secretion from endothelial cells, and choline further increased the VEGF secretion of endothelial cells under hypoxic conditions, suggesting that the mechanism of choline stimulating endothelial cell proliferation might be related to promoting VEGF secretion.

The effect of MLA, an antagonist of $\alpha 7 \mathrm{nAChR}$, on choline was also observed. It was found that the effect of choline on promoting rat artery endothelial cell proliferation under hypoxic conditions was significantly inhibited by MLA $(\mathrm{P}<0.01$; Fig. 6B). This suggested that choline may increase cell proliferation by activating $\alpha 7 \mathrm{nAChR}$.

\section{Discussion}

Hypoxia exposure is continuous when exposed to high altitude; however, it is more common for exposure to be intermittent when 
A

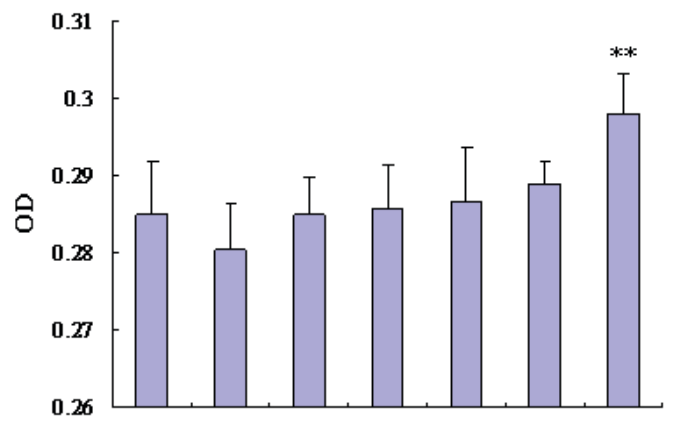

B

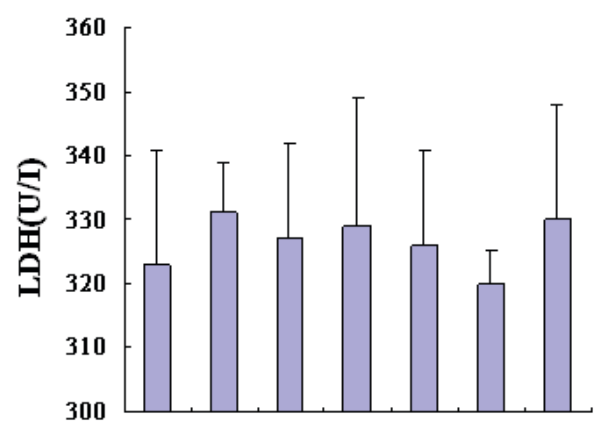

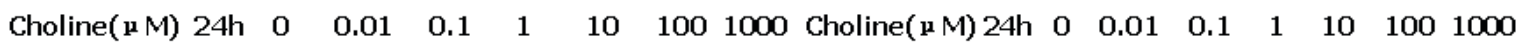

$\mathrm{C}$

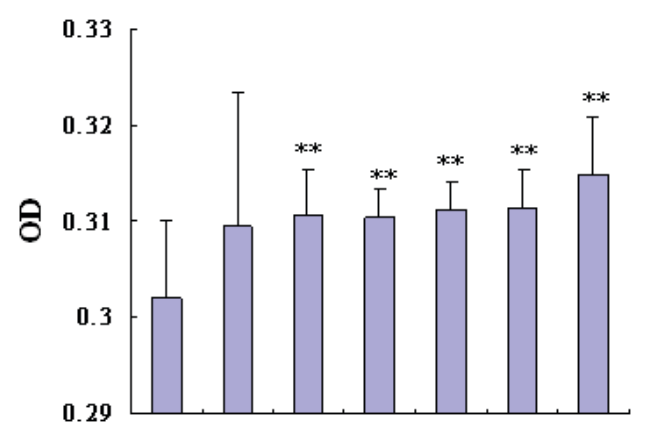

D

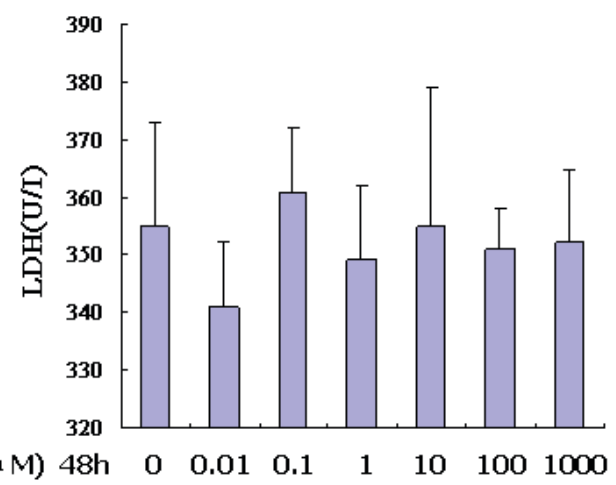

Figure 4. Effects of choline on promoting cell proliferation and protecting against damage under normoxic conditions. (A and B) show MTS assays and LDH activity levels, respectively, when RAECs were treated with choline for $24 \mathrm{~h}$ under normoxic conditions. (C and D) show, MTS assays and LDH activity levels, respectively, when RAECs were treated with choline for $48 \mathrm{~h}$ under normoxic conditions. ${ }^{* *} \mathrm{P}<0.01 \mathrm{vs}$. control. RAEC, rat aortic endothelial cell; $\mathrm{LDH}$, lactate dehydrogenase; OD, optical density.

\section{A}

A $\quad 0.55$
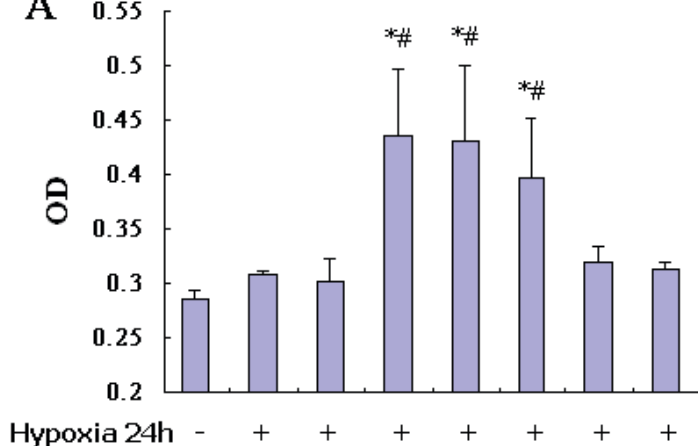

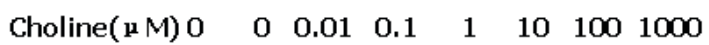

$\mathrm{C}$

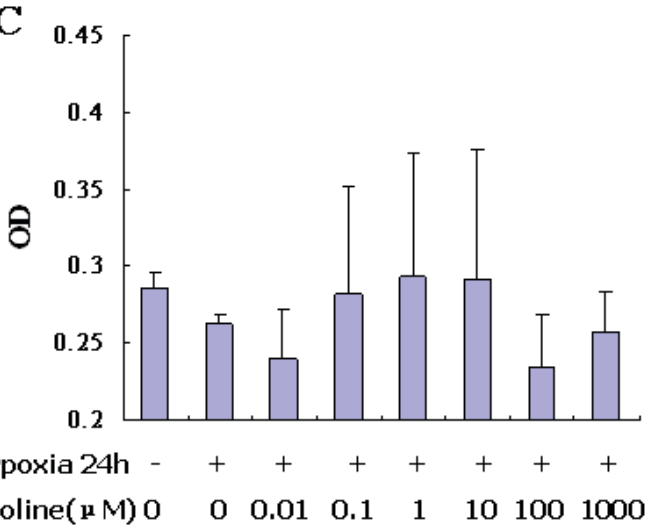

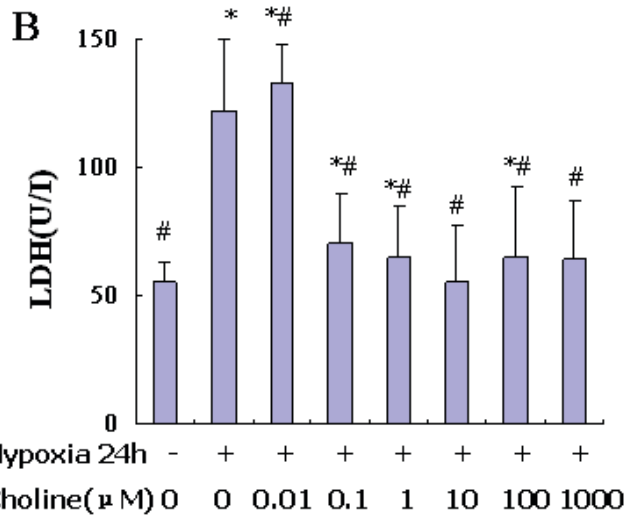

$\mathrm{D}_{300}$

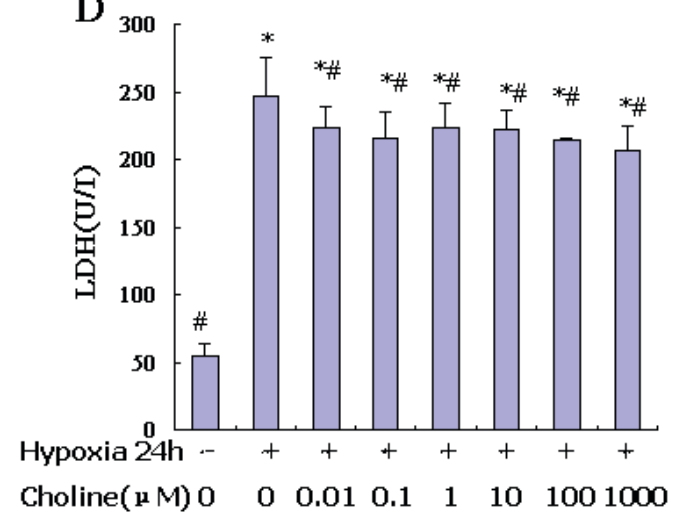

Figure 5. Effects of choline on promoting cell proliferation and protecting against damage under hypoxic conditions. (A and B) MTS assays and LDH activity levels, respectively, when RAECs were treated with choline for $24 \mathrm{~h}$ under hypoxic conditions. (C and D) MTS assays and LDH activity levels, respectively, when RAECs were treated with choline for $48 \mathrm{~h}$ under hypoxic conditions. ${ }^{*} \mathrm{P}<0.05,{ }^{* *} \mathrm{P}<0.01$ vs. control; ${ }^{*} \mathrm{P}<0.05,{ }^{\# \#} \mathrm{P}<0.01$ vs. hypoxia. RAEC, rat aortic endothelial cell; LDH, lactate dehydrogenase. 

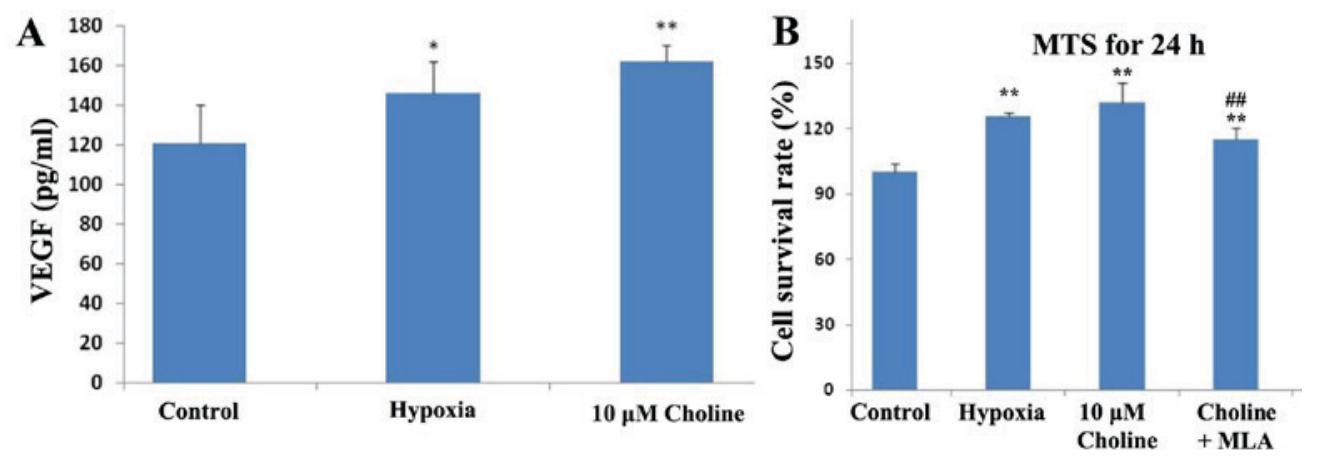

Figure 6. Investigating mechanisms of choline in promoting endothelial cell proliferation. (A) Effects of choline on VEGF secretion by RAECs under hypoxic conditions. (B) Influence of MLA on the choline effects of promoting endothelial cell proliferation in RAECs. ${ }^{*} \mathrm{P}<0.05,{ }^{* *} \mathrm{P}<0.01$ vs. control; ${ }^{\#} \mathrm{P}<0.05$, ${ }^{\# \#} \mathrm{P}<0.01$ vs. Choline group. VEGF, vascular endothelial growth factor; RAEC, rat aortic endothelial cell; MLA, mecamylamine.

it is associated with certain disease states. $\mathrm{CIH}$, in particular, has been the focus of numerous clinical investigations (23-25) and animal model studies (26-29). It has been demonstrated to have epidemiological associations with mortality and morbidity in many acute and chronic diseases, including neurocognitive dysfunction (30-32), numerous cardiovascular disorders (33-35), respiratory diseases $(19,36,37)$ and metabolic disorders $(38,39)$. For example, obstructive sleep apnea (one of the pathological appearances of hypoxia), together with obesity, alcoholism, stress and high cholesterol, is an independent risk factor of cardiovascular and cerebrovascular disease, and closely related to their occurrence (34).

The current study aimed to provide a theoretical foundation for improving the human ability to tolerate hypoxia and effectively protecting against the damage of $\mathrm{CIH}$ to the human body. The effect of $\mathrm{CIH}$ on the ACh-mediated endothelium-dependent vasodilatation function of rat cerebral basilar and mesenteric arterioles was observed through isolated vascular ring perfusion and resistance vessel tension research platforms (21). The vascular endothelial diastolic function is an important indicator of endothelial function (40). The integrity of endothelial cell structure and function are important for maintaining the normal physiological activity of blood vessels, and once damaged, will become an influential factor in the pathogenesis of hypoxia-related diseases. In 1973, Ross and Glomset first proposed the endothelial damage response hypothesis, and since then vascular endothelial function has become a popular research focus in the study of numerous diseases (41).

In the current study, $\mathrm{CIH}$ was found to inhibit endothelium-dependent relaxation of rat cerebral basilar arterioles and mesenteric arterioles, which suggested that $\mathrm{CIH}$ caused damage to the vascular endothelium. The difference in relaxation rates between rat cerebral basilar arterioles and mesenteric arterioles might be caused by the differences of their vascular injuries or their hypoxic sensitivities.

By contrast, results from the current study showed that acute hypoxic exposure had no obvious influence on the rat mesenteric arteriole endothelium-dependent relaxation rate. This suggested that vascular endothelium may only be damaged by long-term hypoxia. Although there was no significant difference between the groups that were exposed to hypoxia for 1 or $3 \mathrm{~h}$, it was speculated that with a prolonged time of hypoxia, the endothelium-dependent relaxation response would have been significantly damaged. However, the vessels were exposed to the external environment directly in the acute hypoxia experiment, which would have inevitably affected the activity of the blood vessels. This prevented further investigation by exposing the arterioles to hypoxic conditions for any longer time periods in this experiment.

As described above, choline, also known as vitamin B4, is an essential nutrient $(10,11)$ which influences important physiological processes such as cell proliferation, differentiation, migration and apoptosis (42), and also participates in physiological functions such as signaling transduction, formation and integrity of cell membranes and ACh synthesis (14). In addition, choline metabolite betaine acts as an alternate methyl donor to folate, providing one methyl group to form methionine from homocysteine; thus, it is a major methyl donor needed for DNA and histone methylation $(15,16)$.

Choline is essential for human beings to maintain their normal physiological function. When dietary choline is deficient, most adult men and postmenopausal women present with organ dysfunction, which manifests in conditions such as fatty liver or muscle damage. A choline-deficient diet during pregnancy may influence fetal cognitive function and visuospatial memory (43-45). It has been reported, however, that hypoxia can reduce the cellular uptake of choline (17). Thus, supplementing choline under hypoxic conditions may effectively prevent a series of problems caused by the lack of choline. In a previous study, it was found that choline increased the intracellular $\mathrm{Ca}^{2+}$ concentration, proliferation and tube formation of endothelial cells; furthermore, in the rat model of acute myocardial infarction, choline similarly enhanced the capillary density in ischemic tissues (46). In the current study, the vasodilator effect of choline was observed in the cerebral basilar arterioles and mesenteric arterioles of rats subjected to $\mathrm{CIH}$ using $\mathrm{ChCl}$, a product form of choline. $\mathrm{ChCl}$ was chosen instead of native choline in this study because it has better stability, it is more easily absorbed into the tissues and causes less irritation to tissues owing to its neutrality in solution (47). In this study, choline caused a significant increase in the dilation of rat cerebral basilar arterioles and mesenteric arterioles damaged by $\mathrm{CIH}$, compared with those in the normoxic control group. Notably, the vasodilatation effect of choline on the normal arterioles was weaker than that on the arterioles injured by CIH. In the acute hypoxic exposure experiments on isolated arterioles, the rat mesenteric 
vascular endothelium-dependent relaxation response induced by choline gradually decreased with the prolonged hypoxia exposure, but no significant differences existed between the groups treated with hypoxia for 1 or $3 \mathrm{~h}$ and the control group. As described above, the acute hypoxia slightly reduced the relaxation rate of the vascular endothelium as the hypoxia exposure time increased, but this reduction was not significant.

The current study found that hypoxic exposure significantly increased levels of LDH in the cell culture supernatants, which suggested hypoxia-induced endothelial cell damage. The results further showed that under both normoxic and hypoxic conditions, choline significantly increased the proliferation of RAECs. This suggested that choline only played a protective role to the endothelial cells subjected to hypoxic injuries, but had no negative effects on normal endothelium. Thus, it is proposed that choline could be developed to treat chronic diseases caused by hypoxia, with low side effects.

The mechanism by which choline protects the endothelial function has not yet been reported. Mehta et al proposed that choline reduces the levels of reactive oxygen species (ROS), thereby reducing damage to the endothelium (48). Hypoxia could induce increased levels of ROS, which would decrease vascular activity and cause damage to vascular endothelial cells. In the current study, treatment with $10 \mu \mathrm{M}$ choline significantly increased the secretion of VEGF in endothelial cells under hypoxic conditions. VEGF promotes endothelial cell proliferation, and the neoformative endothelial cells could supplement or replace the injured or dead endothelial cells caused by hypoxia. Thus, choline may protect the endothelium against hypoxic injuries by ensuring the continuity of the endothelial cell structure and function. Finally, the current study investigated whether choline protects against hypoxic damage via $\alpha 7 \mathrm{nAChR}$. MLA, an antagonist of $\alpha 7 \mathrm{nAChR}$, blocked the increased cell proliferation effect of choline under hypoxic conditions, indicating that choline may be activating the target $\alpha 7 \mathrm{nAChR}$. However, the exact mechanisms of how choline protects endothelial function require further study.

The current study found that ACh-mediated vasodilatation of rat cerebral basilar arterioles and mesenteric arterioles was significantly reduced in the $\mathrm{CIH}$ group compared with the normoxic control group. This indicated that $\mathrm{CIH}$ could cause rat endothelial injuries, but the acute hypoxic exposure of isolated arterioles had no significant effect on ACh-mediated vasodilatation. Furthermore, it was found that choline dilated the rat cerebral basilar arterioles and mesenteric arterioles damaged by $\mathrm{CIH}$ significantly more than those in the normoxic control group, but had no significant dilative effects on isolated arterioles exposed to acute hypoxia. In addition, under hypoxic conditions, choline promoted the proliferation of RAECs and significantly reduced the level of LDH in the cell culture supernatant in vitro. Meanwhile, the effect of choline might be related to its ability to significantly increase the secretion of VEGF and activate $\alpha 7$ $\mathrm{nAChR}$ under hypoxia. This study demonstrated that choline could have protective effects against hypoxic injuries.

\section{Acknowledgements}

This study was supported in part by grants from the National Natural Science Foundation of China (grant nos. 81171870 and 31470061), the Natural Science Foundation of Tianjin (grant no. 11JCYBJC14700) and the Innovation Platform Special Program of Tianjin Science and Technology Innovation System (grant no. 14JCZDJC32700).

\section{References}

1. Cheng F, Lan J, Xia W, Tu C, Chen B, Li S and Pan W: Folic acid attenuates vascular endothelial cell injury caused by Hypoxia via the inhibition of Erk1/2/Nox4/Ros pathway. Cell Biochemistry and Biophysics 74: 205-211, 2016.

2. Negro R: Endothelial effects of antihypertensive treatment: Focus on irbesartan. Vasc Health Risk Manag 4: 89-101, 2008.

3. Venditti P, Pamplona R, Portero-Otin M, De Rosa R and Di Meo S: Effect of experimental and cold exposure induced hyperthyroidism on $\mathrm{H} 2 \mathrm{O} 2$ production and susceptibility to oxidative stress of rat liver mitochondria. Arch Biochem Biophys 447: 11-22, 2006.

4. Xiong M, Cheng GQ, Ma SM, Yang Y, Shao XM and Zhou WH: Post-ischemic hypothermia promotes generation of neural cells and reduces apoptosis by $\mathrm{Bcl}-2$ in the striatum of neonatal rat brain. Neurochem Int 58: 625-633, 2011.

5. Fischer S, Renz D, Wiesnet M, Schaper W and Karliczek GF: Hypothermia abolishes hypoxia-induced hyperpermeability in brain microvessel endothelial cells. Brain Res Mol Brain Res 74: 135-144, 1999.

6. Valbuena G and Walker DH: The endothelium as a target for infections. Annu Rev Pathol 1: 171-198, 2006.

7. Michiels C, Arnould T and Remacle J: Endothelial cell responses to hypoxia: Initiation of a cascade of cellular interactions. Biochim Biophys Acta 1497: 1-10, 2000.

8. Weis SM and Cheresh DA: Pathophysiological consequences of VEGF-induced vascular permeability. Nature 437: 497-504, 2005.

9. Nilsson I, Shibuya M and Wennström S: Differential activation of vascular genes by hypoxia in primary endothelial cells. Exp Cell Res 299: 476-485, 2004.

10. Pitkin R, Allen L, Bailey L and Bernfield M: Dietary Reference Intakes for Thiamin, riboflavin, niacin, vitamin B6, folate, vitamin B12, Pantothenic acid, biotin and choline. National Academy Press, Washington, DC, 2000.

11. Blusztajn JK: Choline, a vital amine. Science 281: 794-795, 1998

12. McCollum EV: A History of Nutrition: The Sequence of Ideas in Nutrition Investigations. Houghton Mifflin, Boston, MA, 1957.

13. Best CH, Hershey JM and Huntsman ME: The effect of lecithine on fat deposition in the liver of the normal rat. J Physiol 75: 56-66, 1932.

14. Zhu X and Zeisel S: Choline and Phosphatidylcholine. Guide To Nutritional Supplements. Elsevier, pp108-113, 2005.

15. Zeisel SH and Blusztajn JK: Choline and human nutrition. Annu Rev Nutr 14: 269-296, 1994.

16. Zeisel SH, Mar MH, Howe JC and Holden JM: Concentrations of choline-containing compounds and betaine in common foods. J Nutr 133: 1302-1307, 2003.

17. Hara T, Bansal A and DeGrado TR: Effect of hypoxia on the uptake of [methyl-3H]choline, [1-14C] acetate and [18F]FDG in cultured prostate cancer cells. Nucl Med Biol 33: 977-984, 2006.

18. Liu J, Wu JQ, Yang JJ, Wei JY, Gao WN and Guo CJ: Metabolomic study on vitamins $\mathrm{B}_{1}, \mathrm{~B}_{2}$, and pp supplementation to improve serum metabolic profiles in mice under acute hypoxia based on ${ }^{1} \mathrm{~h}$ nmr analysis. Biomed Environ Sci 23: 312-318, 2010.

19. Prabhakar NR: Oxygen sensing during intermittent hypoxia: Cellular and molecular mechanisms. J Appl Physiol (1985) 90: 1986-1994, 2001.

20. Neubauer JA: Invited review: Physiological and pathophysiological responses to intermittent hypoxia. J Appl Physiol (1985) 90: 1593-1599, 2001.

21. Ma X, Cheng KT, Wong CO, O'Neil RG, Birnbaumer L, Ambudkar IS and Yao X: Heteromeric TRPV4-C1 channels contribute to store-operated $\mathrm{Ca}(2+)$ entry in vascular endothelial cells. Cell Calcium 50: 502-509, 2011.

22. Brookins Danz ED, Skramsted J, Henry N, Bennett JA and Keller RS: Resveratrol prevents doxorubicin cardiotoxicity through mitochondrial stabilization and the Sirt1 pathway. Free Radic Biol Med 46: 1589-1597, 2009.

23. Younes M, Ostrowski M, Thompson W, Leslie C and Shewchuk W: Chemical control stability in patients with obstructive sleep apnea. Am J Respir Crit Care Med 163: 1181-1190, 2001. 
24. Gozal D, O'Brien L and Row BW: Consequences of snoring and sleep disordered breathing in children. Pediatr Pulmonol Suppl 26: 166-168, 2004

25. Bålfors EM and Franklin KA: Impairment of cerebral perfusion during obstructive sleep apneas. Am J Respir Crit Care Med 150: 1587-1591, 1994.

26. Xu W, Chi L, Row BW, Xu R, Ke Y, Xu B, Luo C, Kheirandish L, Gozal D and Liu R: Increased oxidative stress is associated with chronic intermittent hypoxia-mediated brain cortical neuronal cell apoptosis in a mouse model of sleep apnea. Neuroscience 126: 313-323, 2004.

27. Row BW, Liu R, Xu W, Kheirandish L and Gozal D: Intermittent hypoxia is associated with oxidative stress and spatial learning deficits in the rat. Am J Respir Crit Care Med 167: 1548-1553, 2003

28. Veasey SC, Davis CW, Fenik P, Zhan G, Hsu YJ, Pratico D and Gow A: Long-term intermittent hypoxia in mice: Protracted hypersomnolence with oxidative injury to sleep-wake brain regions. Sleep 27: 194-201, 2004.

29. Prabhakar NR and Kumar GK: Oxidative stress in the systemic and cellular responses to intermittent hypoxia. Biol Chem 385 : 217-221, 2004

30. Verstraeten E: Neurocognitive effects of obstructive sleep apnea syndrome. Curr Neurol Neurosci Rep 7: 161-166, 2007.

31. Beebe DW and Gozal D: Obstructive sleep apnea and the prefrontal cortex: Towards a comprehensive model linking nocturnal upper airway obstruction to daytime cognitive and behavioral deficits. J Sleep Res 11: 1-16, 2002.

32. Cutler MJ, Swift NM, Keller DM, Wasmund WL and Smith ML: Hypoxia-mediated prolonged elevation of sympathetic nerve activity after periods of intermittent hypoxic apnea. J Appl Physiol (1985) 96: 754-761, 2004.

33. Morrell MJ, Finn L, Kim H, Peppard PE, Badr MS and Young T: Sleep fragmentation, awake blood pressure, and sleep-disordered breathing in a population-based study. Am J Respir Crit Care Med 162: 2091-2096, 2000

34. Nieto F, Young TB, Lind BK, Shahar E, Samet JM, Redline S, D'Agostino RB, Newman AB, Lebowitz MD and Pickering TG: ASsociation of sleep-disordered breathing, sleep apnea, and hypertension in a large community-based study. JAMA 283: 1829-1836, 2000.

35. Peppard PE, Young T, Palta M and Skatrud J: Prospective study of the association between sleep-disordered breathing and hypertension. N Engl J Med 342: 1378-1384, 2000.
36. Mitchell GS, Baker TL, Nanda SA, Fuller DD, Zabka AG, Hodgeman BA, Bavis RW, Mack KJ and Olson EB Jr: Invited review: Intermittent hypoxia and respiratory plasticity. J Appl Physiol (1985) 90: 2466-2475, 2001.

37. Mitchell GS and Johnson SM: Neuroplasticity in respiratory motor control. J Appl Physiol (1985) 94: 358-374, 2003.

38. Punjabi NM, Sorkin JD, Katzel LI, Goldberg AP, Schwartz AR and Smith PL: Sleep-disordered breathing and insulin resistance in middle-aged and overweight men. Am J Respir Crit Care Med 165: 677-682, 2002.

39. Resnick HE, Redline S, Shahar E, Gilpin A, Newman A, Walter R, Ewy GA, Howard BV and Punjabi NM; Sleep Heart Health Study: Diabetes and sleep disturbances: Findings from the sleep heart health study. Diabetes Care 26: 702-709, 2003.

40. Pagnin E, Giacon B, Zaghetto F, Vianello D, Bonfante L, Huber W, Antonello A, Semplicini A and Calò L: Arterial hypertension and oxidative stress induced by cyclosporin. Effect of carvedilol. Ann Ital Med Int 16: 101-105, 2001 (In Italian)

41. Ross R and Glomset JA: Atherosclerosis and the arterial smooth muscle cell: Proliferation of smooth muscle is a key event in the genesis of the lesions of atherosclerosis. Science 180: 1332-1339, 1973.

42. Thompson C: Apoptosis in the pathogenesis and treatment of disease. Science 267: 1456-1462, 1995

43. Meck WH and Williams CL: Characterization of the facilitative effects of perinatal choline supplementation on timing and temporal memory. NeuroReport 8: 2831-2835, 1997.

44. Meck WH, Smith RA and Williams CL: Pre- and postnatal choline supplementation produces long-term facilitation of spatial memory. Dev Psychobiol 21: 339-353, 1988.

45. Williams CL, Meck WH, Heyer DD and Loy R: Hypertrophy of basal forebrain neurons and enhanced visuospatial memory in perinatally choline-supplemented rats. Brain Res 794: 225-238, 1998.

46. Li X-W and Wang H: Non-neuronal nicotinic alpha 7 receptor, a new endothelial target for revascularization. Life Sci 78: $1863-1870,2006$

47. Riedesel CC and Hines HM: Studies on the absorption of choline chloride. J Am Pharm Assoc Am Pharm Assoc 42: 579-581, 1953

48. Mehta AK, Arora N, Gaur SN and Singh BP: Choline supplementation reduces oxidative stress in mouse model of allergic airway disease. Eur J Clin Invest 39: 934-941, 2009. 